\title{
Ajwa Dates Ameliorate Myocardial Toxicities Induced by Clozapine in Rats
}

${ }^{1}$ Faiza Khan, ${ }^{2}$ Anila Errum, ${ }^{3}$ Saadia Shahzad Alam, ${ }^{4}$ Gulpash Saghir, ${ }^{2}$ Khadija Mastoor

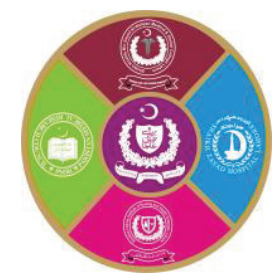

${ }^{5}$ Asma Inam,

${ }^{1}$ Department of Pharmacology, Rashid Latif Medical College, Lahore

${ }^{2}$ Department of Pharmacology, UCMD, University of Lahore

${ }^{3}$ Department of Pharmacology, Shaikh Zayed Medical Complex, Lahore

${ }^{4}$ Department of Pharmacology, Fatima Jinnah Medical University, Lahore

${ }^{5}$ Department of Pharmacology, Azra Naheed Medical College, Lahore

\begin{abstract}
Introduction: Clozapine (CLZ) is a highly effective antipsychotic drug for patients suffering from schizophrenia. However its most important side effect is life-threatening myocarditis. Studies have shown that Clozapine-induced myocarditis is accompanied with an increase in cardiac oxidative stress. Since Ajwa dates have strong antioxidant activity, their potential cardio-protective ability against Clozapine induced myocardial toxicity merits investigations. Aims \& Objectives: To investigate the ameliorating effects of Ajwa dates (Pheonix Dactilyfera) fruit and pit extracts on myocardial toxicities induced by Clozapine in rats. Place and duration of study: Post Graduate Medical Institute, Lahore. January, 2017 to March, 2017. Material \& methods: It was an experimental control group design. 32 female healthy albino rats were randomly assigned to four groups of eight animals each (Table 1). Group 1 the healthy control group, was maintained on standard laboratory diet ad libitum for 21 days, all animals in group 2 the diseased control) were injected with CLZ once daily intraperitoneal (IP) injection of $0.1 \mathrm{ml}$ dose of $25 \mathrm{mg} / \mathrm{kg} /$ day for 21 days. Group 3 was fed with CLZ plus Aqueous ajwa date fruit extract (aq.ADFE) $1 \mathrm{~g} / \mathrm{kg} / \mathrm{d}$ by gastric gavage. Each rat in Group 4 was given CLZ plus aqueous ajwa date pit extract (aq.ADPE) $1 \mathrm{~g} / \mathrm{kg} / \mathrm{d}$ by gastric gavage. All groups were then compared for LDH, MDA, CK-MB, GSH and GSH-Px values on the $22^{\text {nd }}$ day at the end of the study. Results: This study found aqueous extract of Phoenix dactilyfera fruit and pit to reduce myocardial toxicity induced by Clozapine as shown by an improvement in cardiac biochemical and oxidative stress markers of LDH, CKMB, GSH, GSH-Px and MDA. Conclusion: It was concluded that the myocardial toxicity caused by clozapine in rats can be ameliorated by using aqueous Ajwa dates (Phoenix dactilyfera) fruit and pit extracts.
\end{abstract}

Key words: Ajwa Dates, Pheonix dactylifera, Myocardial Toxicity, Clozapine

\section{INTRODUCTION}

Schizophrenia is a major psychotic disorder that typically begins during adolescence or early adulthood $^{1}$. The disease manifests itself as alterations in thoughts and perceptions i.e. delusions, hallucinations and loosening of associations ${ }^{2}$. According to a study of World Health Organization, the disease was projected as the 10th leading cause of YLDs (years lived with disability) in 2013. The main focus of treatment in schizophrenia includes antipsychotic medicines and psychosocial intervention ${ }^{4}$.

The anti-psychotic drugs introduced lately are termed "atypical" or second generation agents (SGAs) that are therapeutically effective in patients showing no response to first generation agents
(FGAs) $)^{5}$. Common examples include Risperidone, Ziprasidone, Olanzapine and Clozapine. Among these, Clozapine has been termed most effective for treating resistant schizophrenia ${ }^{6}$. Clozapine structurally is a tricyclic compound (dibenzodiazepine). It acts mainly by blocking $5 \mathrm{HT}_{2 \mathrm{~A}}$ receptors ${ }^{7}$. In $10 \%$ to $50 \%$ of schizophrenics unresponsive to typical antipsychotic medications, clozapine is an effective alternative $^{8}$. It has been approved by the FDA for treatment of suicidal behaviors in schizophrenics as well as for treatment of severe schizophrenia unresponsive to other medicines ${ }^{4,9}$. It is the most efficacious amongst the atypical antipsychotics in reducing suicidal ideation in schizophrenics ${ }^{7,10}$.

Recent literature has highlighted the cardiovascular complications associated with clozapine particularly myocarditis and cardiomyopathy ${ }^{7,11-13}$. Research suggests that myocarditis despite being a mild 
disease may result in fatal heart failure ${ }^{14}$. Studies have reported myocarditis as one of the major causes of sudden death among young population ${ }^{14,16}$. Cardiotoxicity induced by clozapine is accompanied by elevated oxidative stress and decreased antioxidant defenses ${ }^{13}$.

Natural substances have countless medicinal properties and can cure without any side effects. Cultivated in North Africa and Middle East for at least 5000 years, date is one of the most primitive fruit crops ${ }^{17}$. In the desert region, date is an emblem of life as it can endure drought, high temperatures, and salinity compared to any other fruit ${ }^{18}$. Date fruits are considered to show protective effects against various diseases because of the bioactive non-nutrients generally termed as phytochemicals. These compounds have been gaining increasing importance in the field of medicine due to their cholesterol lowering and anti-oxidant properties and their due role in prevention of diabetes and cardiovascular diseases ${ }^{19,20}$. According to a research, the phytochemicals present in date fruit differ widely in composition and quantity depending upon various factors such as type and variety of date, the stage of ripening, storage and processing etc. Sun drying, for instance is believed to result in loss of carotenoid and anthocyanin content while causing an increase in total polyphenols and phenolic acids $^{21,22}$

Ajwa is the most expensive variety of date palm and a rare cultivar which is delightfully soft and fruity having fine texture and black colour ${ }^{23,24}$. The Ajwa Date is the fruit of female date palm tree (Phoenix dactylifera), belonging to the family Arecaceae and is cultivated only at Al-Madina Al-Nabawiah in Saudi Arabia ${ }^{25}$. The motivation for studying this particular variety came from the sayings of Prophet Muhammad (SAW) about this special date which was planted by his own hands ${ }^{26}$.

According to phytochemical analysis, Ajwa dates have higher content of carbohydrates, minerals, proteins, multivitamins, fats and dietary fibers which make Ajwa superior to other dates ${ }^{23}$. These contain alkaloids, steroids, flavonoids, tannins, phenols and polyphenols that act as antioxidants ${ }^{27,28}$. In a study done on three premium quality dates, Rhutab, Khalas and Ajwa, it was found that Ajwa dates had the highest antioxidant activity (free radical scavenging capacity) and significantly higher levels of total phenolic content ${ }^{29}$. Another recent study concluded Ajwa pits being the richest source when compared for total phenols and flavonoid contents with other local varieties ${ }^{30}$.

Despite the availability of vast literature on date palm's therapeutic properties, the direct effects of date fruit and pit consumption on cardiovascular system remains under-investigated ${ }^{31}$. No study has yet been done regarding protective role of Date palm fruit and pit against Clozapine induced cardiotoxicity. The present study aims to explore this protective role of a particular cultivar of Phoenix dactylifera, the Ajwa dates ${ }^{20}$.

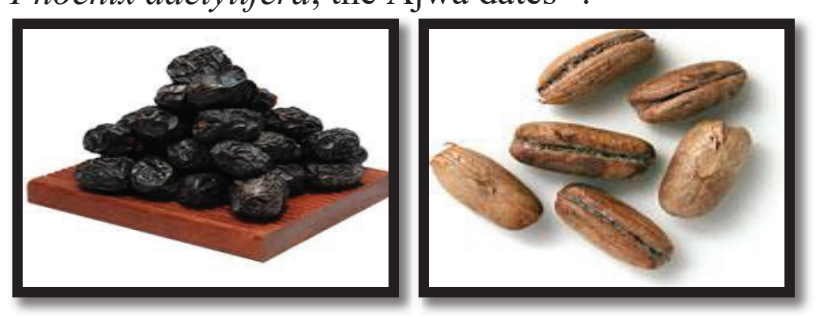

Fig-1: Ajwa Dates Fruits and Pits

\section{MATERIAL AND METHODS}

Plant Material: Ajwa dates were purchased from a renowned dry fruit shop in Lahore i.e. Sadiq Dry Fruit and verified by PCSIR Laboratories, Lahore.

Drugs: Clozapine provided by Mass Pharmaceuticals, Lahore in powdered active principle.

Chemicals: Malondialdehyde, Thiobarbituric acid, Perchloric acid, reduced Glutathione, Ellman's reagent (5, 5- dithiobis-2-nitrobenzoic acid DTNB solution), Hydrogen peroxide, Chloroform in liquid form, Phosphate buffered saline (PBS), Formalin solution, Eosin/hematoxylin stain, Normal saline $(0.9 \% \mathrm{NaCl})$ by, Mass Pharmaceuticals.

Instruments: Eppendorf tubes, Serum vials, Glass slides, Multichannel pipettes, Syringes $5 \mathrm{ml}$ and $10 \mathrm{ml}$, Sterile glass test tubes (Pyrex), Dissection box, Small plastic containers, Insulin syringes, Filter paper, Electronic balance (for measuring the doses of medicine and plant extracts).

Sample Selection: 32 healthy female Sprague dawley albino rats aged 6-7 weeks weighing 150200 gms purchased from University of Veterinary and Animal Sciences Lahore were used in the experiment.

Biochemical Kits: LDH kit (Analyticon, Germany), CK assay kit (Wieners Lab).

Preparation of Medicine and Extracts: CLZ was dissolved in $0.1 \mathrm{M} \mathrm{HCl}$ and $\mathrm{pH}$ balanced (5.9) in phosphate buffered saline (PBS). It was administered in $0.1 \mathrm{ml}$ doses of $25 \mathrm{mg} / \mathrm{kg} / \mathrm{day} \mathrm{IP}^{32}$ as previous research showed that rats could bear far greater ranges of $\mathrm{pH}$ than humans $(4.5-8.0)^{33}$.

Aqueous Extract of Ajwa Date Fruits (aq. ADFE): Flesh of fruits was left in distilled water (1:3) for 48 hours at $4^{\circ} \mathrm{C}$. The whole solution was ground and centrifuged at $4^{\circ} \mathrm{C}$ for $20 \mathrm{~min}$ at 4000 $\mathrm{rpm}$. The supernatant was collected and stored at $80^{\circ} \mathrm{C}$ till use ${ }^{34}$. 
Aqueous Extract of Ajwa Date Pits (aq. ADPE): After separating pits from flesh, the pits were washed with tap water and sun dried. Further drying was done at $50^{\circ} \mathrm{C}$ for $4 \mathrm{hrs}$ in an oven. Pits were then milled by heavy duty grinder. The milled pit was sieved through $1 \mathrm{~mm}$ screens, followed by adding 1 litre hot $\left(80^{\circ} \mathrm{C}\right)$ water onto $50 \mathrm{~g}$ pit powder. The mixture was incubated at $30^{\circ} \mathrm{C}$ for $7 \mathrm{~h}$ while shaken at $100 \mathrm{rpm}$. The extract was filtered through Whatman no.4 filter papers, lyophilized and kept at $-80^{\circ} \mathrm{C}$ until used ${ }^{35}$.

Experimental Setup: The rats were housed in standard polypropylene cages at a controlled room temperature of $25 \pm 10^{\circ} \mathrm{C}$ and relative humidity 60 $70 \%$ at PGMI, Lahore. They were fed standard laboratory diet ad libitum through the entire study duration i.e. 21 days. Animals were kept on a 12hour light-dark schedule $6 \mathrm{am}$ to $6 \mathrm{pm}$ and all experimental testing was conducted during the light phase from 9am to $12 \mathrm{pm}$. Two weeks were given to rats for acclimatization to the new environment before starting the experiment. All efforts were made to minimize animal suffering.

1. Group Formation: Sample was divided into four groups of eight animals each (Table-1). These were given different treatments for 21 days. Group 1 (healthy control) was maintained on standard laboratory diet ad libitum. All animals in group 2 (diseased control group) were injected with CLZ once daily intraperitoneal (IP) injection of $0.1 \mathrm{ml}$ dose of $25 \mathrm{mg} / \mathrm{kg} /$ day. This high dose of CLZ was used for inducing myocarditis based for on an earlier study ${ }^{36}$. Group 3 was administered with CLZ plus aqueous date fruit extract (aq. ADFE) $1 \mathrm{~g} / \mathrm{kg} / \mathrm{d}$ by gastric gavage which was equivalent to 7 dates per person/day ${ }^{35}$. Each rat in Group 4 was given CLZ plus aqueous fruit pit extract (aq. ADPE) $1 \mathrm{~g} / \mathrm{kg} / \mathrm{d}$ by gastric gavage.

2. Blood Sampling: At the end of the study on the $22^{\text {nd }}$ day the anaesthetized animal was placed in dorsal recumbent position. After marking the lower border of sternum, needle of syringe was introduced just to the left of xiphoid process towards heart at 20-30 degrees. By applying negative pressure at least $3 \mathrm{cc}$ of blood was collected from heart in serum vials.

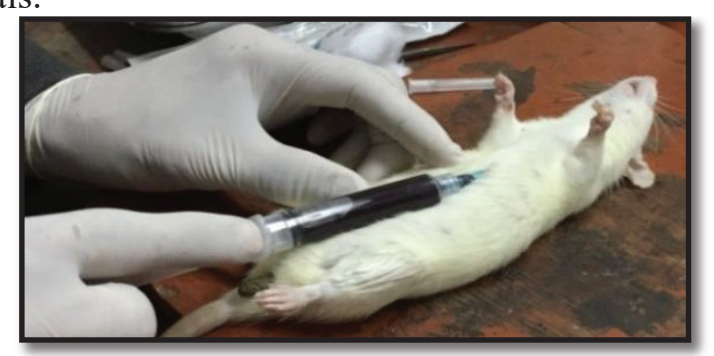

Fig-2: Collection of blood by intra-cardiac puncture
3. Serum Preparation: The blood samples were centrifuged at $3000 \mathrm{rpm}$ for 5 minutes. The serum was then collected with the help of micropipette in eppendorf tubes. The serum was stored in a freezer at $-40^{\circ} \mathrm{Ctill}$ further analysis.

4. Supernatant Preparation: After blood sampling animals were surgically sacrificed. A vertical midline incision was performed to cut sternum, then heart was taken out. The hearts were excised and washed with ice-cold saline blotted with a piece of filter paper and divided into two halves. One half of each heart was homogenized in phosphate buffer $(\mathrm{pH}$ 7.4). The homogenates were centrifuged at $3000 \mathrm{rpm}$ at $4{ }^{\circ} \mathrm{C}$ for $30 \mathrm{~min}$. The supernatants of the homogenates were removed and stored in eppendorf tubes at $-40^{\circ} \mathrm{C}$. The Supernatant was used for biochemical assays.

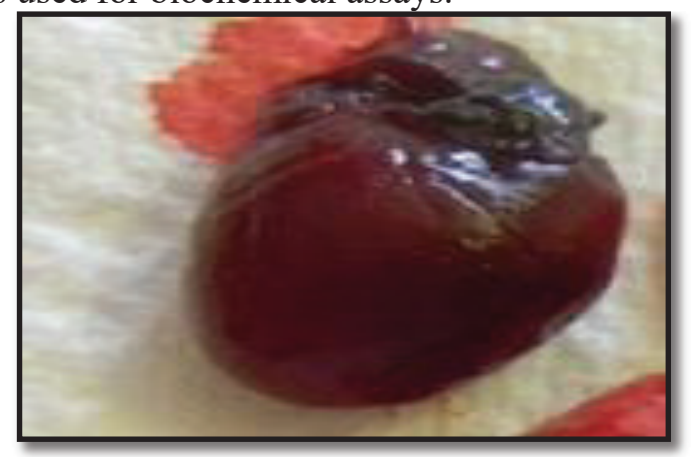

Fig-3: Rat heart placed on a filter paper

\section{Biochemical Parameters:}

1) CK-MB activity in serum was measured by using CK assay kit (Weiners Lab). This assay is based on the conversion of creatine phosphate and ADP by CK-MB to creatine and ATP. The ATP and glucose are converted to ADP and glucose 6 phosphate by hexokinase (HK) and G6PD then oxidizes G6P and reduces NAD to NADH. Rate of $\mathrm{NADH}$ formation, measured at $340 \mathrm{~nm}$, is directly proportional to CK-MB activity ${ }^{37}$.

2) LDH (Lactate Dehydrogenase) activity in rats' serum was measured by LDH kit (Analyticon, Germany). It is the kinetic determination of $\mathrm{LDH}$ activity.

Pyruvate $+\mathrm{NADH}+\mathrm{H}^{+} \leftrightarrow$ Lactate $+\mathrm{NAD}^{+}$

Lactate dehydrogenase catalyzes the conversion from pyruvate to lactate oxidizing $\mathrm{NADH}$ into NAD. The rate of NADH decrease is measured photometrically and is directly proportional to the LDH concentration ${ }^{38}$.

3) Lipid peroxidation was measured in cardiac homogenate (MDA Quantification).The unknown MDA containing samples were first reacted with Thiobarbituric acid at $95^{\circ} \mathrm{C}$. After brief incubation, the samples and standards were read 
spectrophotometrically. MDA content in unknown samples was determined by comparison with predetermined MDA values ${ }^{39}$.

4) Determination of GSH level and GSH-Px activity: (Glutathione and Glutathione peroxidase). For intracellular GSH measurement equal volume of perchloric acid was mixed with cardiac homogenate by vortexing, and was then allowed to stand for 5 min. at room temperature. After centrifugation at $3000 \mathrm{rpm}$, supernatant was collected and was assayed using Ellman's reagent ${ }^{40}$. For GSH-Px activity, enzymatic reaction involving $\beta \mathrm{NADPH}$, GSH, Glutathione reductase and a standard, was initiated by the addition of Hydrogen peroxide. The change in absorbance was measured spectrophotometrically ${ }^{41}$.

\section{Statistical Analysis:}

It was done by using SPSS version 20.0. Based on normality and homogeneity, one way ANOVA was applied for test of difference of mean.

\section{RESULTS}

A tabular description of the various animal groups and the diet they were given is represented in Table-1.

\begin{tabular}{|l|}
\hline \multicolumn{1}{|c|}{$\begin{array}{c}\text { GROUPS } \\
(\mathbf{n = 8})\end{array}$} \\
\hline $\begin{array}{l}\text { GROUP 1 } \\
\text { (CONTROL standard lab. diet) }\end{array}$ \\
\hline GROUP 2 \\
(CLZ only) \\
\hline $\begin{array}{l}\text { GROUP 3 } \\
\text { (CLZ \& aq. ADFE) }\end{array}$ \\
\hline $\begin{array}{l}\text { GROUP 4 } \\
\text { (CLZ \& aq. ADPE) }\end{array}$ \\
\hline
\end{tabular}

The mean values of each group for the various biochemical parameters are illustrated through bar charts. The overall difference among groups was found significant with $p<0.001$. After 3 weeks of treatment with clozapine, group 2 had highest levels of isoenzymes LDH and CK-MB levels of $312.6 \pm 10.5$ and $(332.13 \mathrm{IU} / \mathrm{L})$ respectively than group 1, 3 and group 4 (p-value $<0.001$ ) while group 1 had the lowest. Group 3, and 4 had mean levels close to healthy controls in group 1 (Fig-4). The difference of values LDH, CK-MB between Groups $3 \& 4$ was not statistically significant (pvalues of $0.752,0.914$ respectively).

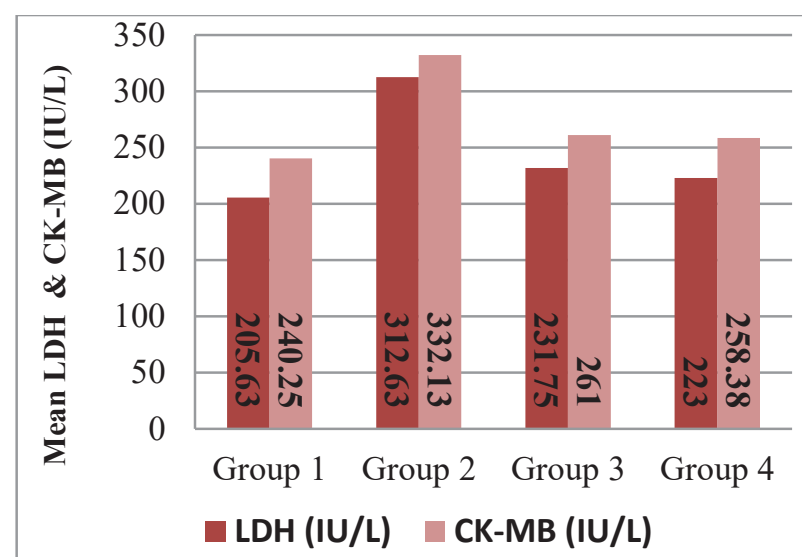

Fig-4: Group-wise comparison of mean LDH \& CK-MB values

The mean MDA levels were similarly noted to be the highest for group 2 at $433.88 \mathrm{umol} / \mathrm{g}$ protein (pvalue $<0.001$ ) and least for group 1 at $321.13 \mathrm{umol} / \mathrm{g}$ protein (p-value $<0.001$ ).(Fig-5). MDA levels of group 3 and 4 were both closer to normal values of Group 1 and the difference between them was not statistically significant p-value 0.999 .

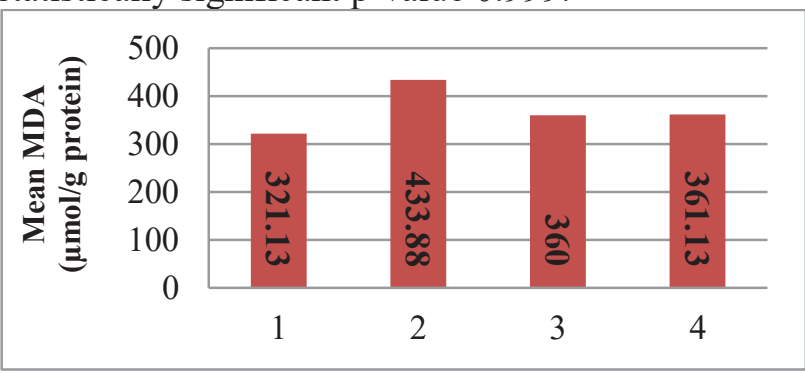

Fig-5: Group-wise comparison of mean MDA values

The GSH value was in reverse order in comparison to previous variables and mean value was lowest for group 2 ( $\mathrm{P}$-value $<0.001)$ and highest for group $1(\mathrm{P}-$ value $<0.001)$, and were recorded to be $17.6 \pm 1.2$ and $34.7 \pm 1.7$ respectively. The difference between GSH value of group 3 and group 4 was not statistically significant (p-value 0.958). The GSHPx levels had almost similar results as for GSH (Fig-6).

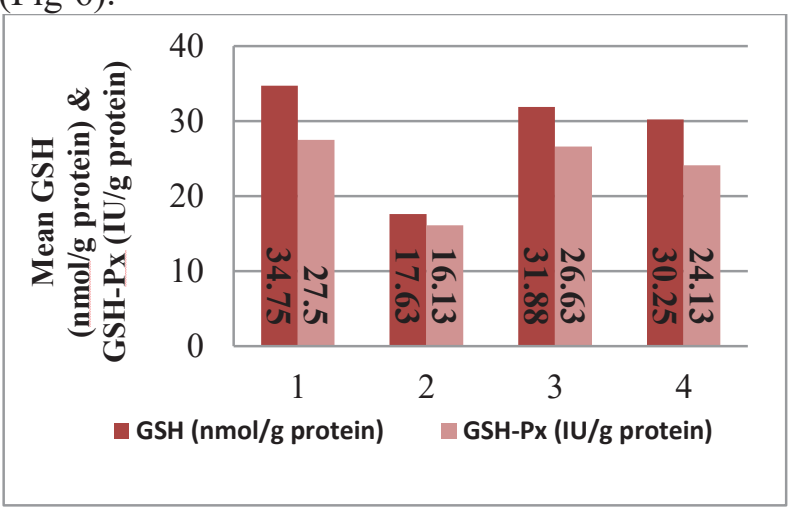

Fig-6: Group-wise comparison of mean GSH \& GSH-Px values 


\section{DISCUSSION}

Clozapine (CLZ) is one of the commonly used SGAs having lesser extra pyramidal side effects ${ }^{42,43}$. However, this potential of CLZ is compromised by its tendency to result in other serious side effects like the life threatening myocarditis ${ }^{44,45}$. Hence the use of CLZ is restricted to patients of treatmentrefractory schizophrenia and for patients with suicidal tendencies. Consequently, there is a dire need to find treatments to counter this life threatening myocarditis caused by CLZ so that the use of this very effective antipsychotic drug can be expanded to treat more patients of schizophrenia. Dates are rich in these bioactive non-nutrients ${ }^{46}$. So, the aim of present study is to explore the effects of various extracts of Ajwa date palm fruit and pit, a particular cultivar of dates superior to all varieties ${ }^{23}$. A healthy control group (group 1) was maintained on standard laboratory diet. Group 2 (diseased control) was given CLZ only in $0.1 \mathrm{ml}$ dose of $25 \mathrm{mg} / \mathrm{kg} /$ day IP (intraperitoneally) for 21 days. $3^{\text {rd }}$ group was given both CLZ and aq. ADFE $(1 \mathrm{gm} / \mathrm{kg} /$ day orally) while Group 4 received CLZ and aq. ADPE $(1 \mathrm{gm} / \mathrm{kg} /$ day orally) for 21 days. No animal loss occured during the study.

\section{Serum LDH and CK-MB Levels}

The elevated levels of LDH and CK-MB are considered an important indicator of early and late cardiac damage, particularly during clinical followup of any drug induced cardiac pathologies ${ }^{47}$. In our study significant differences were found when the groups were tested for serum LDH levels with $\mathrm{p}<0.001$. Group 1 (healthy control) had the lowest LDH levels, while those of group 2 (diseased control) rose by $34 \%$ as compared to group 1 upon CLZ administration. This showed that biochemical derangements had begun to occur with CLZ. LDH levels of group 2 were the highest among all the groups with $p<0.05$. On the other hand, 3 weeks of administering aq. ADFE and aq. ADPE (group $3 \&$ 4) resulted in significant decline of $25 \%$, and $28 \%$ respectively as compared to the diseased control group. A significant decline in CK-MB levels was also noted in groups $3 \& 4$ of $21 \%$ \& $22 \%$ respectively (Fig-4). Phytochemicals present in date fruit and pit could have proven beneficial in this regard as these contain compounds known to have anti-oxidant properties and play an important role in prevention of cardiovascular diseases ${ }^{19}$.

No previous direct research on serum LDH and CKMB levels could be found to support or refute these results proving the current work to be original in its scope.

\section{Oxidative Stress Parameters:}

\section{Lipid Peroxidation Product (MDA)}

Lipid peroxidation is a well-known mechanism of cell damage and oxidative stress. Lipid peroxides decompose to form malondialdehyde ${ }^{48}$. In our study, the levels of MDA were measured in all rats. Our study showed that CLZ injected rats (group 2) $\mathrm{p}<0.001$, had the highest MDA levels with a $26 \%$ increase as compared to the healthy control (group1). After 21 days of treatment, aq. ADFE and aq. ADPE (group $3 \& 4$ respectively) provided less potent antioxidant activity with a decrease in MDA levels to $17 \%$, and $16 \%$ respectively (Fig-5).

\section{GSH}

Glutathione is a fundamental intracellular enzyme that helps in protecting the cells from free radical damage and acts as an antioxidant ${ }^{49}$. In healthy cells, reduced form of glutathione (GSH) is more than $90 \%$ of total glutathione pool. When cell is under oxidative stress, GSH levels drop down ${ }^{50}$. In our study GSH levels were observed.

Group 1 (healthy control) had the highest GSH levels while group 2 (in which CLZ was used for inducing cardiotoxicity) had the lowest levels with p-value $<0.001$. Thus a drop of $97 \%$ was recorded in GSH levels due to CLZ generated oxidative stress. GSH levels of group 3 and 4 were closer to healthy control group proving antioxidant activity in Ajwa dates (Fig-6).

\section{GSH-Px}

Like GSH, the main role of GSH-Px is to protect the cell from oxidative damage. We measured GSH-Px levels in all rats and it also showed heartening results. The healthy control (group 1) had the highest GSH-Px levels. The least GSH-Px levels were observed for group 2 (where myocarditis had been induced by giving CLZ) as reflected by a drop of $70 \%$ versus group 1 .

The cardiac GSH-Px of rats in Group 3 (aq. ADFE) and group 4 (aq. ADPE) exhibited improvement in of $65 \%$ and $49 \%$ respectively reflecting perhaps that pit extract had lesser antioxidant activity than the fruit extract (Fig-6).

This showed that aq. ADFE had the highest antioxidant and free radical scavenging ability. These results were in agreement to previous results. Aq. extract of Ajwa date fruit had the highest free radical scavenging ability ${ }^{51}$.

\section{CONCLUSION}

In conclusion, the myocardial toxicity caused by Clozapine in rat model was improved by consumption of aqueous extracts of Ajwa dates pit and fruit extract. It was demonstrated by an 
improvement in cardiac biochemical and oxidative stress marker levels of LDH, CK-MB, GSH, GSHPx and MDA values in experimental groups 3 and 4, which were administered these Ajwas aqueous extracts.

\section{REFERENCES}

1. Katzung BG, Masters SB, Trevor AJ. Basic and clinical pharmacology. 12th ed. Philadelphia: McGraw Hill; 2012.

2. Ayuso-Mateos JL, Gutierrez-Recacha P, Haro JM, Chisholm D. Estimating the prevalence of schizophrenia in Spain using a disease model. Schizophr Res. 2006 Sep; 86(1):194-201.

3. Institute for Health Metrics and Evaluation (Internet). Washington: Institute for Health Metrics and Evaluation; 2015 (date unknown). Available from http://www.healthdata.org/news-release/deathrates-decline-nonfatal-diseases-and-injuriestake-bigger-toll-health-worldwide

4. U.S. Department of Health and Human Services, National Institute of Mental Health. (2015). NIMH Strategic Plan for Research (NIH Publication No. 15-3517). Retrieved from

http://www.nimh.nih.gov/health/publications/sc hizophrenia-booklet-12-2015/index.shtml

5. Liperoti R, Pedone C, Corsonello A. Antipsychotics for the treatment of behavioral and psychological symptoms of dementia (BPSD). CurrNeuropharmacol. 2008 Jun; 6(2):117-24.

6. Abdel Hamid OI, Ahmed MG, Hassaneine HM, Rashed HE. Evaluation of the role of captopril on clozapine-induced cardiotoxicity and hematotoxicity in adult male albino rats. Toxicology Research and Application. 2017; $1: 1-11$

7. Merrill DB, Dec GW, Goff DC. Adverse cardiac effects associated with clozapine. J Clin 5Psychopharmacol. 2005 Feb; 25(1):32-41.

8. Lewis SW, Barnes TR, Davies L, Murray RM, Dunn G, Hayhurst KP, et al. Randomized controlled trial of effect of prescription of clozapine versus other second-generation antipsychotic drugs in resistant schizophrenia. Schizophr Bull. 2006 Oct; 32(4):715-23.

9. Chakos M, Lieberman J, Hoffman E, Bradford D, Sheitman B. Effectiveness of secondgeneration antipsychotics in patients with treatment-resistant schizophrenia: a review and meta-analysis of randomized trials. Am J Psychiatry. 2001 Apr; 158(4):518-26
10. Leucht S, Komossa K, Rummel-Kluge C, Corves C, Hunger H, Schmid F, et al. A metaanalysis of head-to-head comparisons of second-generation antipsychotics in the treatment of schizophrenia. Am J Psychiatry. 2009 Feb; 166(2):152-163.

11. Barry AR, Windram JD, Graham MM. Clozapine-associated myocarditis: Case report and literature review. Can J Hosp Pharm. 2015; 68(5):427.

12. Kilian JG, Kerr K, Lawrence C, Celermajer DS. Myocarditis and cardiomyopathy associated with clozapine. The Lancet. 1999 Nov; 354(9193):1841-5.

13. Abdel-Wahab BA, Abdalla ME, El-khawanki MM. Does clozapine induce myocarditis, myocardial oxidative stress and DNA damage in rats? Egyptian Journal of Forensic Sciences. 2014 Sep; 4(3):75-82.

14. Kytö V, Saraste A, Voipio-Pulkki LM, Saukko $P$. Incidence of fatal myocarditis: a populationbased study in Finland. Am J Epidemiol. 2007; 165(5):570-4.

15. Neuspiel DR, Kuller LH. Sudden and unexpected natural death in childhood and adolescence. JAMA. 1985; 254(10):1321-5.

16. Eckart RE, Scoville SL, Campbell CL, Shry EA, Stajduhar KC, Potter RN, et al. Sudden death in young adults: A 25-year review of autopsies in military recruits. Ann Intern Med. 2004; 141(11):829-34.

17. Chao CT, Krueger RR. The date palm (Phoenix dactylifera L.): Overview of biology, uses, and cultivation. Hort Science. 2007 Aug; 42(5):1077-82.

18. Zabar AF, Borowy A. Cultivation of date palm in Iraq. Annales Universitatis Mariae CurieSkłodowska. Sectio EEE: Horticultura. 2012; $1(22)$.

19. Vayalil PK. Date fruits (Phoenix Dactyliferalinn): $\mathrm{n}$ emerging medicinal food. Cri Rev Food ScNutr. 2012; 52:249-71.

20. Al-Alawi RA, Al-Mashiqri JH, Al-Nadabi JS, Al-Shihi BI, Baqi Y. Date palm tree (Phoenix dactylifera L.): natural products and therapeutic options. Front Plant Sci. 2017 May; 8:845.

21. Jain, S. M. "Health Benefits of date palm: Phytochemicals and their functions. "Department of Agricultural Sciences, University of Helsinki, PL-27, Helsinki, Finland (2013).

22. Vinson JA, Zubik L, Bose P, Samman N, Proch J. Dried fruits: excellent in vitro and in vivo antioxidants. J Am CollNutr. 2005 Feb; 24(1):44-50. 
23. Sheikh BY, Elsaed WM, Samman AH, Sheikh BY, Ladin AM. Ajwa dates as a protective agent against liver toxicity in rat. EurSci J. 2014 Feb; Special Edition 3.

24. Ajwa Dates Natural Cure For Heart Diseases retrieved from

http://ajwadatesnaturalcureforheartdiseases.blog spot.com/2013/04/ajwa-dates-natural-cure-forheart.html

25. Al-Shahib W, Marshall RJ. The fruit of date palm: Its possible use as the best food for the future? Int J Food SciNutr 2003; 54:247-59.

26. Ali SA, Parveen N, Ali AS. Links between the Prophet Muhammad (PBUH) recommended foods and disease management: a review in the light of modern super foods. Int J Health Sci. 2018 Mar; 12(2):61.

27. Singh RP, Murthy CKN, Jayaprasha GK. Studies on the antioxidant activity of pomegranate (punicagranatum) peel and seed extracts using in vitro models. J Agric Food Chem. 2002; 50:81-6.

28. Zhang CR, Aldosari SA, Vidyasagar PS, Nair KM, Nair MG. Antioxidant and antiinflammatory assays confirm bioactive compounds in Ajwa date fruit. J Agric Food Chem. 2013 Jun; 61(24):5834-40.

29. Mansouri A, Embarek G, Kokkalou E, Kefalas P. Phenolic profile and antioxidant activity of the Algerian ripe date palm fruit (Phoenix dactilyfera). Food Chem 2005; 89(3):411-20.

30. Khalid S, Ahmad A, Kaleem M. Antioxidant capacity and phenolic contents of ajwa date and their effect on lipo-protein profile. FFHD 2017 Jun; 7(6):396-410.

31. Alhaider IA, Mohamed ME, Ahmed KK, Kumar AH. Date palm (phoenix dactylifera) fruits as a potential cardioprotective agent: the role of circulating progenitor cells. Front Pharmacol. 2017 Sep;8:592.

32. Abdel-Wahab BA, Metwally ME, El-khawanki MM, Hashim AM. Protective effect of captopril against clozapine-induced myocarditis in rats: role of oxidative stress, proinflammatory cytokines and DNA damage. ChemBiol Interact 2014; 216:43-52.

33. Nebendahl, K. Routes of administration. In: Georg JK, editor. Handbook of Experimental Animals. London: Academic Press; 2000. p. 463-83.

34. Abul-Soad AA. Date Palm in Pakistan, Current Status and Prospective. (2010). USAID Firms Project.

35. Jivan MJ, Yarmand MS, Madadlou A. Encapsulation of date palm pit extract via particulation of starch nanocrystals in a micoemulsion. Inter J Food Sci Technol. 2014; 49: 920-23.

36. Wang JF, Min JY, Hampton TG, Amende I, Yan X, Malek S, et al., Clozapine induced myocarditis: role of catecholamines in a murine model, Eur J Pharmacol. 2008; 592(1-3):123-7.

37. Bishop C, Chu TM, Shihabi ZK. Single stable reagent for creatine kinase assay. Clin Chem. 1971 Jun; 17(6):548-550.

38. Whitaker, J.F. A general colorimetric procedure for the estimation of enzymes which are linked to the NADH/NAD+ system. Clin. Chim. Acta. $1969 ; 24: 23-27$.

39. Ohkawa H, Ohishi N, Yagi K: Assay for lipid peroxides in animal tissues by thiobarbituric acid reaction. Anal Biochem. 1979; 95:351-358.

40. Griffith OW. Determination of glutathione and glutathione disulfide using glutathione reductase and 2-vinylpyridine. Anal. Biochem. 1980; 106:207-212.

41. Paglia DE, Valentine WN. Studies on the quantitative and qualitative characterization of erythrocyte glutathione peroxidase. J Lab Clin Med. 1967; 70(1):158-69.

42. Factor SA. Pharmacology of atypical antipsychotics. ClinNeuroPharmacol. 2002; 25(3):153-7.

43. Abidi S, Bhaskara SM. From chlorpromazine to clozapine - antipsychotic adverse effects and the clinician's dilemma. Can J Psychiatry. 2003; 48:749-55.

44. Ronaldson KJ, Fitzgerald PB, McNeil JJ. Clozapine-induced myocarditis, a widely overlooked adverse reaction. ActaPsychiatr Scand. 2015 Oct; 132(4): 231-40.

45. Youssef DL, Narayanan P, Gill N. Incidence and risk factors for clozapine-induced myocarditis and cardiomyopathy at a regional mental health service in Australia. Australas Psychiatry. 2015 Sep; 1039856215604480.

46. Al-Farsi MA, Lee CY. Nutritional and functional properties of dates: a review. Crit Rev Food SciNutr. 2008 Oct; 48(10):877-87.

47. Tahraoui A, El-Hilaly J, Israili ZH and Lyoussi B. Ethnopharmacological survey of plants used in traditional treatment of hypertension and diabetes in South-Eastern Morocco (Errachidia Province). J Ethnopharmacol. 2007; 110(1):10517.

48. Armstrong D, Browne R. The analysis of free radicals, lipid peroxides, antioxidant enzymes and compounds related to oxidative stress as applied to the clinical chemistry laboratory. In 
Free radicals in diagnostic medicine 1994 (pp. 43-58). Springer US.

49. Miguel-Carrasco JL, Monserrat MT, Mate A, Vázquez CM. Comparative effects of captopril and 1-carnitine on blood pressure and antioxidant enzyme gene expression in the heart of spontaneously hypertensive rats. Eur J Pharmacol. 2010 Apr; 632(1):65-72.

50. Liu J, Yeo HC, Övervik-Douki E, Hagen T, Doniger SJ, Chu DW, et al. Chronically and acutely exercised rats: biomarkers of oxidative stress and endogenous antioxidants. J Appl Physiol. 2000 Jul; 89(1):21-8.

51. Saleh EA, Tawfik MS, Abu-Tarboush HM. Phenolic contents and antioxidant activity of various date palm (Phoenix dactylifera L.) fruits from Saudi Arabia. Food Nutr Sci. 2011 Dec; 2011.

\section{The Authors:}

Dr. Faiza Khan,

Assistant Prof., Pharmacology Department, Rashid Latif Medical College, Lahore.
Dr. Anila Errum,

Assistant Prof., Pharmacology Department, UCMD, University of Lahore.

Prof. Saadia Shahzad Alam, Head of Department Pharmacology, Shaikh Zayed Medical Complex Lahore.

Dr. Gulpash Saghir,

Assistant Prof., Pharmacology Department, Fatima Jinnah Medical University, Lahore.

Dr. Asma Inam,

Assistant Prof., Pharmacology Department, Azra Naheed Medical College, Lahore.

Dr. Khadija Mastoor, Associate Prof., Pharmacology Department, UCMD, University of Lahore.

\section{Corresponding Author:}

Dr. Faiza Khan, Assistant Professor, Pharmacology Department, Rashid Latif Medical College, Lahore.

E-mail: drfaizakhan@hotmail.com 